\title{
Hypothyroidsm with Recurrent Hypokalemic Paralysis
}

\author{
Pruthviraj Chauhan ${ }^{1}$, Ajay Naxane ${ }^{2}$ \\ ${ }^{1}$ Junior resident, Department of General Medicine, SBKS MIRC, Pipariya, Waghodia, Vadodara \\ ${ }^{2}$ Assistant prof, Department of Nephrology, SBKS MISC, Pipariya, Waghodia, Vadodara
}

\begin{abstract}
Hypokalemic paralysis represents a medical emergency requiring both rapid diagnosis and treatment. The cause of this paralytic disorder may be genetic or acquired. Sudden onset of weakness is triggered by stress such as viral illness, fatigue, fight, emotional disturbance and medications like insulin, beta-2 agonists and steroids. This transient and episodic neurological condition is commonly associated with Thyrotoxicosis. Hypothyroidism presenting as recurrent hypokalemic paralysis is rare in the literature. We report a case of 38 year old female with sudden onset of weakness in lower extremities, no sensory deficits and normal higher mental function. There was no enlargement of thyroid gland. Laboratory evaluation revealed low serum potassium. Patient was diagnosed having chronic thyroiditis with high thyroid stimulating hormone and thyroid related antibodies. Follow up shows satisfactory result with thyroxine replacement. It is an extremely rare and unusual presentation of hypothyroidism with hypokalemic paralysis.
\end{abstract}

Keywords: Hypothyroidism, Recurrent Hypokalemic Paralysis

\section{Introduction}

Hypokalemic periodic paralysis, the most common periodic paralysis with a prevalence of 1 in $100,000 .^{1,2,3}$, is also a rare channelopathy. It can result from reduced potassium intake, increased translocation from extracellular spaces into the cells (as a transient condition) or, most commonly, from increased gastrointestinal or urinary losses. Increased potassium secretion in the distal nephron may account for such losses, for example, with the intake of diuretics or because of mineralocorticoid excess. ${ }^{4}$ Hypokalemic paralysis may be caused by a short-term shift of potassium into cells, seen in hypokalemic periodic paralysis (caused by familial periodic paralysis or thyrotoxic periodic paralysis); Thyrotoxicosis is the most common cause of secondary hypokalemic periodic paralysis. Recurrent hypokalemic paralysis is an extremely unusual presentation of hypothyroidism.

\section{Case Report}

A 38 year old female presented with acute onset of $\mathrm{B} / \mathrm{L}$ lower extremity weakness, inability to walk, and profound fatigue since two days. Patient had been having intermittent leg cramps on and off since past 2 years, also had a history of flaccid paralysis 6-8 month back, and was treated with intravenous potassium supplement after which she had a complete recovery.

There was no history of fever, diarrhea, vomiting, rash or abdominal pain, no history of polyuria, polydipsia, thirst, history of altered sensorium, convulsion, visual or respiratory weakness, no history of drug intake or alcohol abuse.

On physical examination, she appeared weak and was able to stand with support. Her vital signs were: Temperature $98.7^{\circ} \mathrm{F}$, heart rate $50 / \mathrm{min}$, respiratory rate $20 / \mathrm{min}$, BP $118 / 50$ $\mathrm{mmHg}$, and $\mathrm{O} 2$ saturation $99 \%$ on room air. Lungs were clear, heart sounds were normal, abdomen was soft, non tender with normal bowel sound. On central nervous system examination, higher mental functions were normal, no cranial nerve involvement, motor strength in distal upper extremities 4/5 grade, in proximal upper extremities $3 / 5$ grade, in distal lower extremities $4 / 5$ grade, and in proximal lower extremities $1 / 5$ grade. There were diminished deep tendon reflexes, bilateral flexor plantar, and no sensory involvement.

Laboratory investigation as mention in Table 1.

Table 1

\begin{tabular}{|c|c|}
\hline $\mathrm{CBC}$ & HB:13.9gm/dl, TC:7.9 * 109/L, PLATELETS:207 * 109/L,MCV: $86.3 \mathrm{fl}, \mathrm{MCH} 28.8 \mathrm{pg}, \mathrm{MCHC}: 34.6 \mathrm{gm} / \mathrm{dl}$ \\
\hline ESR & $45 \mathrm{ml} / \mathrm{h}$ \\
\hline Urine routine & albumin + , sugar-absent, pus cell1-2-3wbc/hpf. \\
\hline S. electrolytes & $\mathrm{Na}-138 \mathrm{mmol} / \mathrm{L}, \mathrm{K}-1.8 \mathrm{mmol} / \mathrm{L}, \mathrm{Cl}-98 \mathrm{mmol} / \mathrm{L}$ \\
\hline Renal function & Serum creatinine $0.7 \mathrm{mg} / \mathrm{dl}$, blood urea $27 \mathrm{mg} / \mathrm{dl}$ \\
\hline liver function & SGPT-23 U/L; SGOT - 19 U/L; S.Bilirubin $-0.4 \mathrm{mg} / \mathrm{dl}$; direct $-0.2 \mathrm{mg} / \mathrm{dl}$;indirect $-0.2 \mathrm{mg} / \mathrm{dl}$. \\
\hline total protein & $6.90 \mathrm{gm} / \mathrm{dl} ;$ albumin $-4.4 \mathrm{gm} / \mathrm{dl} ; \mathrm{globulin}-2.50 \mathrm{gm} / \mathrm{dl} \mathrm{A} / \mathrm{G}-1.76$ \\
\hline S.TSH & serum TSH $>100 \mathrm{mIU} / \mathrm{L}$, serum antiTPO antibody titre was $287 \mathrm{IU} / \mathrm{ml}$ \\
\hline Serology & HIV-negative; HBsAG - negative; HCV - negative \\
\hline Lipid profile & Cholesterol - $97 \mathrm{mg} / \mathrm{dl}$;Triglycerides - $154 \mathrm{mg} / \mathrm{dl}$;HDL-C -38 mg/dl;LDL-C - $28.2 \mathrm{mg} / \mathrm{dl}$;VLDL - $30.8 \mathrm{mg} / \mathrm{dl}$. \\
\hline \multicolumn{2}{|c|}{ Arterial blood gas $\mathrm{pH} 7.36, \mathrm{Pco} 236 \mathrm{mmHg}, \mathrm{Po} 297 \mathrm{mmHg}$, and bicarbonate $24 \mathrm{mEq} / \mathrm{L}$} \\
\hline Others & serium calcium- $10 \mathrm{mg} / \mathrm{dl}$, serum magnesium- $2.2 \mathrm{mg} / \mathrm{dl}$ \\
\hline
\end{tabular}




\section{International Journal of Science and Research (IJSR) \\ ISSN (Online): 2319-7064 \\ Index Copernicus Value (2015): 78.96 | Impact Factor (2015): 6.391}

Her electrocardiogram showed normal sinus rhythm without features of hypokalemia (i.e. no flattening of $\mathrm{T}$ wave, inverted $\mathrm{T}$ wave, $\mathrm{U}$ wave, depression of ST segment, decreased QRS voltage or prolonged PR or QT interval), USG and chest $\mathrm{x}$ ray were normal. Further investigations: creatinine phosphokinase $241 \mathrm{U} / \mathrm{L}, 24 \mathrm{hr}$ urinary potassium excretion was $16 \mathrm{meq} / \mathrm{l}$, urine $\mathrm{pH} 7.4$, specific gravity 1.012 ; urinary calcium was within normal limit. The computed tomography scan abdomen was normal. Her plasma rennin was measured normal $(2.4 \mathrm{ng} / \mathrm{ml} / \mathrm{h})$.

Table 2

\begin{tabular}{|c|c|c|c|c|}
\hline \multicolumn{5}{|c|}{ Selected laboratory daily investigation } \\
\hline & Day 1 & Day 2 & Day 3 & Day12 \\
\hline Sodium & 138 & 142 & 145 & 140 \\
\hline Potassium & 1.8 & 2.6 & 3.8 & 4.2 \\
\hline Chloride & 98 & 110 & 114 & 104 \\
\hline Creatinine & 1.2 & 1.0 & 1.0 & 0.8 \\
\hline
\end{tabular}

Hypokalemic paralysis was diagnosed based on clinical and biochemical parameters and was treated with infusion potassium chloride at $20 \mathrm{ml} / \mathrm{hr}$ (40meq potassium chloride in $40 \mathrm{ml} \mathrm{NS}, 80 \mathrm{meq} \mathrm{KCl}$ to be replaced in $24 / \mathrm{hr}$ ), oral and infusion supplementation of $\mathrm{KCl}$ for 3 days that lead to clinical and biochemical improvement. Patient was also started on tab levothyroxine $100 \mathrm{mcg}$, and was discharged on oral syrup potassium chloride and tab levothyroxine and reviewed after 4 weeks. Patient serum potassium level and serum TSH level became normal. Patient potassium supplementation was stopped and levothyroxine was continued, there was no further complain of weakness, muscle cramp during the follow up of 1.5 years.

\section{Discussion}

Secondary hypokalemic periodic paralysis is less common. Clues indicating a secondary cause are the lack of family history and the time of onset of symptoms. Patients who have their first attack of weakness in adulthood should be screened carefully for a secondary cause. Secondary hypokalemic periodic paralysis is non-genetic in origin and results from causes such as thyrotoxicosis, barium poisoning, primary hyperaldosteronism, diuretic abuse, renal tubular acidosis, barter syndrome, and gastrointestinal diseases. ${ }^{3}$

In this case patient was admitted with the PARAPARESIS, laboratory studies showed hypokalemia, normal creatinine kinase; rules out possibility of a myopathy, absence of nausea, vomiting, constipating, hypochloremia, and hyponatremia rule out Bartter syndrome, normal serum magnesium and urinary calcium excretion rule out Gitelman's syndrome, there was no metabolic acid-base disturbances that rule out possibility of renal tubular acidosis, though urinary potassium was lower side, in CT scan abdomen adrenal were normal and no characteristic feature of hyperaldosteronism like hypertension and polyuria were present.

The levels of thyroid hormones and TSH values in this patient indicate severe deficiency of thyroxine. The presence of autoimmune thyroiditis is indicated by the high titer positivity of anti-TPO antibodies in serum.
Final diagnosis: Recurrent hypokalemic paralysis in hypothyroidsm.

\section{Conclusion}

Hypokalemic periodic paralysis though common among Indian population varies greatly in disease spectrum and magnitude in our country due to the heterogeneous pattern of etiology. The association of periodic hypokalemic paralysis with hypothyroidism has not been established till now.

\section{References}

[1] Stern R, Cox M, Feig PU, Singer I: Internal potassium balance and the control of the plasma potassium concentration. Medicine 60: 339-354, 1981

[2] Alkabie JM, Mushtaq a, Fatma N et.al "Hypokalemic periodic paralysis: a case series, review of the literature and update of management". European Journal of Emergency Medicine 2010; 17:45-47.

[3] Perazella MA, Rastegar A: Disorders of potassium and acid-base metabolism inassociation with renal disease. In: Diseases of the kidney, $8^{\text {th }}$ ed., edited by Schrier RW, 2006.

[4] Soule BR, Simone LN, "Hypokalemic Periodic Paralysis: a case report and review of the literature. Cases Journal 2008; 1:256. 